\title{
Características de carcaça de ovinos em crescimento alimentados com rações contendo farelo de babaçu
}

\section{Antônio Robson Bezerra Xenofonte ${ }^{1}$, Francisco Fernando Ramos de Carvalho², Ângela Maria Vieira Batista ${ }^{2}$, Geovergue Rodrigues de Medeiros ${ }^{3}$}

\author{
1 Programa de Pós-Graduação da UFRPE; Escola Agrotécnica Federal do Crato. \\ 2 Departamento de Zootecnia da UFRPE. \\ ${ }^{3}$ Escola Agrotécnica Federal de Codó, MA.
}

RESUMO - Avaliaram-se as características, os rendimentos e as medidas lineares de carcaça de 24 ovinos sem padrão racial definido (SPRD), não-castrados, com idade inicial de 4,6 $\pm 0,8$ meses e peso vivo inicial de $20 \pm 3,25 \mathrm{~kg}$, confinados em baias individuais e alimentados com rações contendo 0, 10, 20 ou 30\% de farelo de babaçu. Utilizou-se delineamento em blocos casualizados, com quatro tratamentos e seis repetições. Houve efeito linear decrescente dos níveis de farelo de babaçu sobre o peso de corpo vazio, o peso vivo ao abate e os pesos de carcaça quente e fria. Os pesos da meia-carcaça, de paleta, costelas (da $1 \underline{a}$ a $5 \underline{a}$ e da $6 \underline{a}$ a $13 \underline{a}$ ), serrote, lombo e perna também decresceram de forma linear, enquanto o peso do pescoço foi influenciado de forma quadrática pelos níveis de farelo de babaçu. Os rendimentos dos cortes não foram influenciados pelos níveis do farelo de babaçu: as médias foram de 20,$47 ; 8,65 ; 6,94 ; 9,71 ; 10,36 ; 9,11$ e $33,07 \%$ para paleta, pescoço, costela ( $1 \stackrel{a}{a} 5 \underline{a})$, costela (6 a $13 \underline{a})$, serrote, lombo e perna, respectivamente. Entre as medidas biométricas na carcaça, houve efeito linear decrescente para compacidade da carcaça, área de olho-de-lombo, perímetro da garupa, comprimento de perna e comprimento interno da carcaça. Níveis de farelo de babaçu superiores a $10 \%$ na dieta afetam negativamente os pesos e rendimentos, bem como os cortes comerciais e as medidas lineares, de carcaças de ovinos sem padrão racial definido em terminação.

Palavras-chave: cortes comerciais, dietas, medidas lineares, rendimento de carcaça

\section{Carcass characteristics of growing sheep fed diets with different babassu meal levels}

\begin{abstract}
The carcass characteristics, yields and linear measurements of 24 non-castrated non defined breed lambs (SPDR) with $4.8 \pm 0.8$ months of age and mean initial live weight of $20.45 \pm 3.25$ were evaluated. The animals were kept in individual stalls and fed with diets containing 0, 10, 20 and 30\% of babassu meal. A block randomized design, with six replicates and four treatments was used. A linear decreasing effect of the babassu meal on the empty-body-weight, live weight at slaughter, and cold and hot carcass weight was observed. The half-carcass weight, shoulder weight, ribs (from $1^{\text {st }}$ to $5^{\text {th }}$ and from $6^{\text {th }}$ to $\left.13^{\text {th }}\right)$, braes, loin and leg, also showed decreasing linear effect with babassu meal levels. The neck weight presented quadratic effect. Dressing cuts were not influenced by babassu meal levels (averages of 20.47, 8.65, 6.94, 9.71, $10.36,9.11$ and $33.07 \%$ for shoulder, neck, ribs (from $1^{\text {st }}$ to $5^{\text {th }}$ ), ribs (from $6^{\text {th }}$ to $13^{\text {th }}$ ), breast, loin and leg, respectively). For the carcass measurement, there was linear decreasing effect for the carcass compactness, rib eye area, hind perimeter, leg length and carcass internal length. Diets with babassu meal levels higher than $10 \%$ affected negatively weights and yields, as well the commercial cuts and measurements of the carcass of sheep in feedlot.
\end{abstract}

Key Words: carcass yield, commercial cuts, diets, linear measurements

\section{Introdução}

A carne ovina tem importante função socioeconômica como fonte de proteína de alto valor biológico. Nos últimos anos, a ovinocultura tem passado por transformações visando incrementar sua eficiência e produtividade.
No Nordeste brasileiro, o consumo de carne ovina ainda é baixo, o que está associado à menor oferta e à qualidade do produto comercializado, que muitas vezes é originada de animais velhos com baixa qualidade de carcaça, resultantes de deficientes critérios de seleção para o abate, a estocagem e a comercialização. De acordo com Siqueira

Este artigo foi recebido em 1/12/2006 e aprovado em 15/7/2008. Correspondências devem ser enviadas para: ffr.carvalho@dz.ufrpe.br 
et al. (2001), é fundamental a padronização das carcaças conforme tamanho, percentual de músculos, cobertura de gordura subcutânea e teor de gordura adequado ao mercado.

A carcaça é o componente do peso vivo de maior valor comercial. Todavia, o valor individual de um ovino para produção de carne é estimado por meio do rendimento de carcaça, que expressa a relação percentual entre os pesos de carcaça e do animal. Vários fatores afetam as características quali-quantitativas da carcaça, entre eles, o genótipo, o peso ao abate, a idade e a nutrição (Silva Sobrinho, 2001).

Uma carcaça de boa qualidade possui elevada proporção de músculos, reduzida proporção de ossos e cobertura de gordura subcutânea capaz de evitar desidratação excessiva e escurecimento da carne quando mantida em câmara fria (Osório et al., 2002).

Por outro lado, apesar de a alimentação ser um dos principais componentes de um sistema de produção, no Nordeste brasileiro ainda é fator fortemente restritivo na produção de carne ovina, em virtude da baixa disponibilidade e do elevado custo, principalmente de alimentos concentrados convencionais, como o milho e a soja.

Assim, é crescente a utilização de alimentos alternativos na terminação de ovinos como forma de reduzir os custos de produção. O farelo de babaçu, por exemplo, é um subproduto agroindustrial bastante disponível nos estados do Piauí e Maranhão. Sousa Júnior (2003) concluiu que o uso de farelo de babaçu até o nível de $20 \%$ não interferiu nas características da carcaça de ovinos Santa Inês.

Este trabalho foi realizado com o objetivo de avaliar o rendimento e as características de carcaça de ovinos em crescimento alimentados com diferentes níveis de farelo de babaçu.

\section{Material e Métodos}

O trabalho foi realizado no Setor de Ovinocaprinocultura da Escola Agrotécnica Federal, localizada na cidade do Crato, estado do Ceará, na microrregião do Cariri mesoregião do Araripe, tendo como coordenadas geográficas, latitude $7^{\circ} 14^{\prime \prime}$ e longitude; 39²14" em relação a Greenwich, com a altitude de $450 \mathrm{~m}$. A região apresenta, ainda, clima quente e seco e temperatura média anual de $26^{\circ} \mathrm{C}$ com clima quente e seco (IBGE, 2006).

Foram utilizados 24 ovinos sem padrão racial definido (SPRD), machos não-castrados em crescimento, com 4,6 \pm 0,8 meses de idade e peso inicial de $20,0 \pm 3,25 \mathrm{~kg}$, confinados em baias individuais medindo $0,60 \times 2,0 \mathrm{~m}$, providas de bebedouros e comedouros.

Após pesagem e identificação, os animais foram tratados contra ecto e endoparasitas, vacinados contra clostridioses e receberam uma dose de complexo vitamínico. O experimento teve duração de 60 dias: 10 dias para adaptação às dietas e ao manejo e 50 dias de confinamento para avaliação.

As rações experimentais foram compostas de raspa de mandioca, farelo de soja, grão de milho, farelo de babaçu (0, 10, 20 ou 30\%), feno de capim-colonião (Panicum maximum Jack), uréia e calcário (Tabela 1). As rações experimentais (Tabela 2) foram formuladas para os animais atingirem ganhos em peso de $150 \mathrm{~g} / \mathrm{dia}$, de acordo com o NRC (1985). Durante o experimento, os animais receberam água e sal mineral à vontade.

$\mathrm{O}$ fornecimento das dietas experimentais foi feito às $8 \mathrm{~h} 30$ e às $15 \mathrm{~h} 30$, na forma de dieta completa. O alimento ofertado e as sobras foram pesados diariamente para cálculo do consumo voluntário e reajuste da quantidade oferecida, estabelecendo-se $10 \%$ de sobras.

Tabela 1 - Composição dos ingredientes das rações experimentais

\begin{tabular}{|c|c|c|c|c|c|c|c|c|}
\hline \multirow[t]{2}{*}{ Constituinte } & \multicolumn{8}{|c|}{ Ingrediente } \\
\hline & Milho moído & Farelo de soja & Feno de & capim-colonião & Farelo de babaçu & Raspa de mandioca & Uréia & Calcário \\
\hline MS (\%) & 88,29 & 89,81 & & 89,78 & 90,33 & 87,41 & 100 & 100 \\
\hline MO (\% MS) & 99,68 & 95,90 & & 92,46 & 98,40 & 99,53 & - & - \\
\hline PB (\% MS) & 10,00 & 52,02 & & 7,27 & 20,66 & 4,78 & 260,00 & - \\
\hline $\mathrm{EE}(\% \mathrm{MS})$ & 4,02 & 1,62 & & 2,20 & 5,81 & 0,50 & - & - \\
\hline FDN (\% MS) & 24,07 & 18,29 & & 71,00 & 78,45 & 24,34 & - & - \\
\hline $\mathrm{FDNP}_{\mathrm{P}}^{\mathrm{a}}(\% \mathrm{MS})$ & 22,99 & 15,32 & & 70,0 & 68,88 & 23,85 & - & - \\
\hline FDA (\% MS) & 5,32 & 10,11 & & 49,31 & 48,12 & 5,85 & - & - \\
\hline CNF (\% MS) & 62,67 & 26,94 & & 12,71 & 33,35 & 70,00 & - & - \\
\hline CHOT (\% MS) & 85,66 & 42,26 & & 82,99 & 71,93 & 94,25 & - & - \\
\hline MM (\% MS) & 0,32 & 4,10 & & 7,54 & 1,60 & 0,47 & - & 100 \\
\hline $\mathrm{NDT}^{\mathrm{b}}(\% \mathrm{MS})$ & 87,24 & 81,54 & & 52,00 & 49,38 & 72,27 & - & \\
\hline
\end{tabular}

MS = matéria seca $; \mathrm{MO}=$ matéria orgânica; $\mathrm{PB}=$ proteína bruta $; \mathrm{EE}=$ extrato etéreo; FDN = fibra em detergente neutro; FDNPp = FDN corrigida para proteína; FDA = fibra

em detergente ácido; CNF = carboidratos não-fibrosos; CHOT = carboidratos totais; $\mathrm{MM}=$ matéria mineral; NDT = nutientes digestíveis totais.

a Valadares Filho (2002)

b Estimado pela equação de Weiss (1999). 
Tabela 2 - Composição das dietas experimentais, com base na MS

\begin{tabular}{lcccc}
\hline Ingrediente & \multicolumn{4}{c}{ Nível de farelo de babaçu (\%) } \\
\cline { 2 - 5 } & 0 & 10 & 20 & 30 \\
\hline Grão de milho moído & 32,20 & 38,00 & 41,00 & 42,20 \\
Farelo de soja & 16,00 & 13,00 & 11,00 & 8,00 \\
Feno de capim-colonião & 30,00 & 25,00 & 18,20 & 10,00 \\
Farelo de babaçu & 0,00 & 10,00 & 20,00 & 30,00 \\
Raspa de mandioca & 20,00 & 12,20 & 8,00 & 8,00 \\
Uréia & 0,80 & 0,80 & 0,80 & 0,80 \\
Calcário calcítico & 1,00 & 1,00 & 1,00 & 1,00 \\
Composição & & & & \\
Matéria orgânica & 96,08 & 96,44 & 96,89 & 97,46 \\
Matéria seca & 89,01 & 89,17 & 89,28 & 89,31 \\
Proteína bruta & 15,04 & 15,38 & 16,01 & 16,04 \\
Extrato etéreo & 2,31 & 2,93 & 3,43 & 3,83 \\
Fibra em detergente & 36,84 & 40,08 & 42,44 & 44,20 \\
neutro & & & & \\
FDN corrigida para & 35,62 & 38,02 & 39,53 & 40,50 \\
proteína & & & & \\
Fibra em detergente ácido & 19,29 & 21,19 & 22,36 & 22,68 \\
Carboidratos totais & 78,09 & 77,49 & 76,80 & 76,95 \\
Carboidratos não-fibrosos & 42,30 & 42,37 & 43,24 & 45,47 \\
Matéria mineral & 3,12 & 2,76 & 2,31 & 1,73 \\
Nutrientes digestíveis & 71,18 & 70,50 & 69,85 & 69,13 \\
totais & & & & \\
\hline & & \multicolumn{3}{c}{}
\end{tabular}

Após a fase experimental, os animais foram pesados para obtenção do peso final (PF)e, em seguida, submetidos a jejum de sólidos por 18 horas. Decorrido esse período, os animais foram novamente pesados para obtenção do peso ao abate (PA) visando determinar o percentual de perda por jejum $(\mathrm{PJ})$, calculado pela seguinte equação: $\mathrm{PJ}(\%)=$ $(\mathrm{PF}-\mathrm{PA}) \times 100 / \mathrm{PF}$.

$\mathrm{O}$ abate foi realizado com atordoamento, seguido de sangria pelo corte da carótida e jugular. O sangue foi recolhido em recipiente previamente tarado, para posterior pesagem. Após a esfola e evisceração, foram retiradas a cabeça, com secção na articulação atlanto-ocipital, e as patas, seccionadas nas articulações carpo e tarsometatarsianas, registrando-se em seguida o peso da carcaça quente (PCQ). $\mathrm{O}$ trato gastrintestinal (TGI) foi pesado cheio e vazio para determinação do peso do corpo vazio (PCVZ) e do rendimento biológico ou verdadeiro $(\mathrm{RV}(\%)=\mathrm{PCQ} / \mathrm{PCVZ} \times 100)$.

As carcaças foram resfriadas em câmara frigorífica por 24 horas, em temperatura de $4^{\circ} \mathrm{C}$, com as articulações tarsometatarsianas distanciadas $14 \mathrm{~cm}$, por meio de ganchos próprios. Decorrido esse período, foram tomadas as seguintes medidas lineares na carcaça: comprimento interno = distância entre o bordo anterior da sínfise ísquio-pubiano até o bordo anterior da primeira costela; profundidade do tórax $=$ distância máxima entre o esterno e o dorso da carcaça; largura do tórax = largura máxima da carcaça ao nível das costelas; comprimento da perna $=$ distância entre $\mathrm{o}$ trocânter maior do fêmur até a junção tarsometatarsiana; circunferência da perna com perímetro da perna em sua largura máxima e largura da garupa (largura máxima entre os trocânteres de ambos os fêmures). Posteriormente, as carcaças foram pesadas para obtenção do peso de carcaça fria $(\mathrm{PCF})$ e cálculo da perda por resfriamento $(\mathrm{PR}, \%=$ $P C Q-P C F / P C Q \times 100)$. Foram calculados os rendimentos de carcaça quente $(\mathrm{RCQ}, \%=\mathrm{PCQ} / \mathrm{PA} \times 100)$ e fria $(\mathrm{RCF}, \%=$ $\mathrm{PCF} / \mathrm{PA} \times 100$ ), bem como oíndice de compacidade da carcaça (ICC, $\mathrm{kg} / \mathrm{cm}=\mathrm{PCF} /$ comprimento interno da carcaça fria) .

As carcaças foram, então, divididas ao meio e as meias-carcaças pesadas e seccionadas em sete regiões anatômicas, segundo metodologia proposta por ColomerRocher et al. (1987).

As regiões foram as seguintes: pescoço, que correspondeu à região das sete vértebras cervicais; paleta, obtida pela desarticulação da escápula; costelas verdadeiras, que possui como base óssea as cinco vértebras torácicas; costelas falsas, da região localizada entre a $6^{\underline{a}}$ e a $13^{\text {a }}$ vértebra torácica; lombo, que compreende as seis vértebras lombares; perna, obtida pela secção entre a última vértebra lombar e a primeira sacra; e serrote, obtido do corte em linha reta, iniciando-se no flanco até a extremidade cranial do manúbrio do esterno.

O peso individual de cada corte, composto pelos cortes efetuados nas meias-carcaças esquerda e direita, foi registrado para cálculo de sua proporção em relação à soma das duas meias-carcaças, obtendo-se assim, o rendimento comercial dos cortes da carcaça.

Na meia-carcaça esquerda também foi efetuado um corte transversal, na secção entre a 12 $\underline{a}$ e 13 $\underline{a}$ costelas, para mensuração da área de olho-de-lombo (AOL) do músculo Longissimus dorsi, por meio do traçado do contorno do músculo em folha plástica de transparência, para posterior determinação da área por meio de um planímetro digital, utilizando-se média de cinco leituras. A mensuração da gordura de cobertura sobre a secção também foi obtida no músculo Longissimus dorsi, por meio de paquímetro.

Odelineamento experimental foi de blocos casualizados, com quatro tratamentos e seis repetições, de modo que os blocos foram formados de acordo com o peso inicial dos animais. Além da análise de variância, foi realizada análise de regressão considerando os níveis de farelo de babaçu na dieta.

Os critérios utilizados na escolha das equações foram o comportamento biológico, o coeficiente de determinação $\left(\mathrm{r}^{2}\right)$ e a significância, para os parâmetros de regressão, obtida pelo teste "t - Student", para os níveis de 5\% de probabilidade. As análises estatísticas foram realizadas com auxílio computacional do programa SAEG (2001). 


\section{Resultados e Discussão}

Os pesos dos animais e das carcaças e os rendimentos de carcaça quente e fria decresceram de forma linear $(\mathrm{P}<0,05)$ conforme aumentaram os níveis de farelo de babaçu na dieta. Os animais mantidos com as dietas com $30 \%$ de farelo de babaçu ganharam em média apenas $50 \mathrm{~g} / \mathrm{dia}$, resultando em baixo peso ao abate e da carcaça, o que refletiu diretamente no rendimento de carcaça fria, que ficou em torno de $39,67 \%$. Esse valor também é baixo se comparado aos 47,07; 43,06 e 44,28\% obtidos com 0,10 e $20 \%$ de farelo de babaçu nas dietas, respectivamente (Tabela 3 ).

Esses resultados são reflexo da baixa ingestão de energia pelos animais mantidos com as dietas com maiores percentuais de farelo de babaçu ( 20 e $30 \%$ ), as quais continham em torno de 69\% de NDT ou 2,5 Mcal de energia metabolizável, bem como maiores percentuais de FDN (42,44 e 44,20\%, respectivamente). O aumento do nível energético da dieta é importante para melhora do peso da carcaça de ovinos, como relatam Alves et al. (2003) e Gonzaga Neto et al. (2006).

Por outro lado, a diferença entre o peso ao abate e o peso da carcaça quente resulta em 14,82; 16,59; 11,95 e $10,88 \mathrm{~kg}$ nos respectivos níveis de farelo de babaçu utilizados. Essa diferença corresponde ao peso dos demais componentes do peso vivo, como os órgãos e vísceras, entre outros. Osório et al. (2002) afirmaram que, para valorizar a qualidade total do animal, deve-se considerar o "quinto quarto" (os não-componentes da carcaça), e não apenas a carcaça ou o peso vivo, e que o peso da carcaça fria é mais recomendado.
$\mathrm{O}$ peso ao abate tem sido associado à proporção de músculo e gordura na carcaça. O peso ótimo de abate, principalmente de ovinos deslanados, deve ser definido para cada raça, considerando as preferências dos consumidores. Zapata et al. (2001) reportam que o peso de abate na Região Nordeste tem sido próximo dos $28-30 \mathrm{~kg}$, que resulta em carcaça com 12 a $14 \mathrm{~kg}$. Figueiredo et al. (1982) verificaram que, em pastagem nativa, o melhor peso de abate foi de $25 \mathrm{~kg}$, alcançado por ovinos Santa Inês, com 6 a 7 meses de idade.

O rendimento verdadeiro (RV), a perda por resfriamento (PR) e a perda ao jejum (PJ) não foram influenciados pelos níveis de farelo de babaçu na dieta (Tabela 3) e apresentaram médias de 56,07; 4,74 e 6,06\%, respectivamente. Para a perda por resfriamento, houve grande variação entre os animais que receberam mesmo nível de farelo de babaçu, resultando em coeficientes de variação muito altos. Além disso, fatores como a baixa cobertura de gordura das carcaças e a velocidade do ar da câmara fria podem ter contribuído para essa ocorrência.

Houve efeito linear decrescente $(\mathrm{P}<0,05)$ para peso de meia-carcaça fria, paleta, costelas ( 1 a a $13^{a}$ ) , serrote, perna, lombo e pescoço (Tabela 4). Essa redução no peso dos cortes está diretamente relacionada ao peso da carcaça dos animais, que foi menor nos animais alimentados com as rações com níveis acima de $20 \%$ de farelo de babaçu.

O pescoço apresentou valores de 0,$56 ; 0,60 ; 0,42 \mathrm{e}$ $0,30 \mathrm{~kg}$ para os respectivos níveis de farelo de babaçu estudados. A perna foi o corte mais pesado e com o maior rendimento percentual, o que é importante, pois é uma região com maior musculosidade e maior rendimento da parte comestível (Silva Sobrinho, 2001).

Tabela 3 - Características de carcaça de ovinos mantidos com dietas contendo farelo de babaçu

\begin{tabular}{|c|c|c|c|c|c|c|c|}
\hline & \multicolumn{4}{|c|}{ Nível de farelo de babaçu (\%) } & \multirow[t]{2}{*}{$\mathrm{CV}(\%)$} & \multirow[t]{2}{*}{ Equação de regressão } & \multirow[t]{2}{*}{$r^{2}$} \\
\hline & 0 & 10 & 20 & 30 & & & \\
\hline Peso vivo final, $\mathrm{kg}$ & 30,46 & 32,15 & 24,28 & 19,62 & 10,33 & $\hat{\mathrm{Y}}=33,3627-0,429827 * \mathrm{FB}$ & 0,93 \\
\hline Peso vivo ao abate, $\mathrm{kg}$ & 29,58 & 30,0 & 22,70 & 18,64 & 10,98 & $\hat{\mathrm{Y}}=31,2288-0,398066^{*} \mathrm{FB}$ & 0,87 \\
\hline Peso do corpo vazio, $\mathrm{kg}$ & 25,47 & 24,10 & 18,93 & 14,38 & 11,14 & $\hat{\mathrm{Y}}=26,4687-0,3811948 * \mathrm{FB}$ & 0,93 \\
\hline Peso de carcaça quente, $\mathrm{kg}$ & 14,76 & 13,41 & 10,75 & 7,76 & 13,34 & $\hat{\mathrm{Y}}=15,2269-0,236683 * \mathrm{FB}$ & 0,98 \\
\hline Peso de carcaça fria, $\mathrm{kg}$ & 13,92 & 12,91 & 10,05 & 7,46 & 11,47 & $\hat{\mathrm{Y}}=14,4235-0,222192 * \mathrm{FB}$ & 0,97 \\
\hline Rendimento de carcaça quente, $\%$ & 49,84 & 44,70 & 47,41 & 41,24 & 7,08 & $\hat{\mathrm{Y}}=49,2654-0,230932 * \mathrm{FB}$ & 0,65 \\
\hline Rendimento de carcaça fria, \% & 47,07 & 43,06 & 44,28 & 39,67 & 4,51 & $\hat{\mathrm{Y}}=46,6701-0,209738 * \mathrm{FB}$ & 0,78 \\
\hline Rendimento verdadeiro, $\%$ & 56,85 & 55,68 & 56,77 & 53,97 & 5,44 & $\hat{\mathrm{Y}}=56,07^{\mathrm{ns}}$ & - \\
\hline Perda por resfriamento, $\%$ & 5,39 & 3,67 & 6,11 & 3,80 & 78,70 & $\hat{\mathrm{Y}}=4,74 \mathrm{~ns}$ & - \\
\hline Perda por jejum, $\%$ & 5,97 & 6,72 & 6,61 & 4,94 & 28,46 & $\hat{\mathrm{Y}}=6,06^{\mathrm{ns}}$ & - \\
\hline
\end{tabular}

FB = nível de farelo de babaçu.

* Significativo a 5\% de probabilidade pelo teste t.

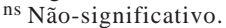


Tabela 4 - Peso e rendimento dos cortes regionais da carcaça de ovinos mantidos com dietas contendo farelo de babaçu

\begin{tabular}{|c|c|c|c|c|c|c|c|}
\hline \multirow[t]{2}{*}{ Variável } & \multicolumn{4}{|c|}{ Nível de farelo de babaçu (\%) } & \multirow[t]{2}{*}{$\mathrm{CV}(\%)$} & \multirow[t]{2}{*}{ Equação de regressão } & \multirow[t]{2}{*}{$r^{2}$} \\
\hline & 0 & 10 & 20 & 30 & & & \\
\hline Peso da meia-carcaça, kg & 6,85 & 6,34 & 4,95 & 3,70 & 10,22 & $\hat{Y}=7,08601-0,107631 * F B$ & 0,97 \\
\hline Paleta, kg & 1,33 & 1,25 & 1,05 & 0,81 & 15,23 & $\hat{Y}=1,37153-0,0174175^{*} \mathrm{FB}$ & 0,96 \\
\hline Pescoço, kg & 0,56 & 0,60 & 0,42 & 0,30 & 16,54 & $\hat{\mathrm{Y}}=1,24525-0,0214775^{*} \mathrm{FB}$ & 0,93 \\
\hline Costelas $\left(1^{\mathrm{a}}-5^{\mathrm{a}}\right), \mathrm{kg}$ & 0,48 & 0,43 & 0,35 & 0,26 & 19,13 & $\hat{\mathrm{Y}}=0,492358-0,00743711 * \mathrm{FB}$ & 0,99 \\
\hline Costelas $\left(6^{\mathrm{a}}-13^{\mathrm{a}}\right), \mathrm{kg}$ & 0,67 & 0,64 & 0,48 & 0,34 & 14,35 & $\hat{\mathrm{Y}}=0,703809-0,0112276^{*} \mathrm{FB}$ & 0,94 \\
\hline Serrote, $\mathrm{kg}$ & 0,76 & 0,63 & 0,53 & 0,37 & 15,40 & $\hat{\mathrm{Y}}=0,763491-0,127736 * \mathrm{FB}$ & 0,99 \\
\hline Lombo, $\mathrm{kg}$ & 0,64 & 0,61 & 0,44 & 0,32 & 13,98 & $\hat{\mathrm{Y}}=0,671663-0,112598 * \mathrm{FB}$ & 0,95 \\
\hline Perna, kg & 2,29 & 2,06 & 1,65 & 1,23 & 12,56 & $\hat{\mathrm{Y}}=1,234138-0,0354674 * \mathrm{FB}$ & 0,98 \\
\hline \multicolumn{8}{|l|}{ Rendimento dos cortes, $\%$} \\
\hline Paleta, \% & 19,40 & 19,66 & 21,24 & 21,59 & 12,56 & $\hat{Y}=20,47$ & - \\
\hline Pescoço, \% & 8,19 & 9,42 & 8,54 & 8,44 & 15,95 & $\hat{Y}=8,65$ & - \\
\hline Costelas $(1 \stackrel{\mathrm{a}}{-} 5 \underline{\mathrm{a}}), \%$ & 7,04 & 6,75 & 6,95 & 7,01 & 14,13 & $\hat{\mathrm{Y}}=6,94$ & - \\
\hline Costelas (6-13-13 $), \%$ & 9,74 & 10,09 & 9,69 & 9,30 & 7,25 & $\hat{\mathrm{Y}}=9,71$ & - \\
\hline Serrote, $\%$ & 11,07 & 9,92 & 10,62 & 9,84 & 8,30 & $\hat{\mathrm{Y}}=10,36$ & - \\
\hline Lombo, \% & 9,36 & 9,52 & 8,90 & 8,64 & 9,98 & $\hat{\mathrm{Y}}=9,11$ & - \\
\hline Perna, \% & 33,32 & 32,38 & 33,46 & 33,12 & 5,55 & $\hat{\mathrm{Y}}=33,07$ & - \\
\hline
\end{tabular}

FB = nível de farelo de babaçu.

* Significativo ao nível de 5\% de probabilidade pelo teste t.

ns Não-significativo.

Em termos percentuais, verifica-se que os níveis de farelo de babaçu não influenciaram os cortes de paleta, pescoço, serrote, costelas, perna e lombo em relação à meia-carcaça.

Furusho-Garcia et al. (2004) mencionam que a proporção da costela/fralda aumenta em relação ao peso da carcaça fria. Analisando os pesos dos cortes em relação à meia-carcaça e considerando o seu valor comercial, observa-se que a soma dos cortes considerados de primeira (pernil e lombo) foi de 2,93;2,66;2,09 e 1,55 kg, respectivamente, para os níveis de $0,10,20$ e $30 \%$ de farelo de babaçu, o que representa rendimento de 42,$77 ; 41,95 ; 42,22$ e 41,89\%, respectivamente. As costelas e paletas, consideradas cortes de segunda categoria, somaram, nas diferentes dietas experimentais, 2,49; 2,32; 1,87 e 1,42 kg, com rendimentos de 36,26; 36,54; 37,83 e $38,27 \%$, respectivamente.

Zapata et al. (2001) relataram que os cortes de maior valor comercial da carcaça ovina são pernil, paleta e lombo e que ovinos Morada Nova, variedade branca, apresentaram valores de 32,2 a $32,7 \%$ para o pernil; 19,9 a $21,4 \%$ para a paleta; e 10,3 a 11,1\% para o lombo, em relação à carcaça fria. Neste estudo, foram observados rendimentos aproximados para o pernil e a paleta. Essa semelhança está associada ao porte dos ovinos estudados, próximos ao dos Morada
Nova. Kirton et al. (1996) reportaram que também ocorrem pequenas variações nas proporções dos cortes quando são realizados no mesmo ponto anatômico.

Houve efeito linear decrescente $(\mathrm{P}<0,05)$ para o comprimento interno de carcaça, o comprimento de perna, o perímetro de garupa, a área de olho-de-lombo e a compacidade de carcaça (Tabela 5). As demais variáveis não foram influenciadas pelo nível de inclusão do farelo de babaçu nas dietas, apresentando médias de 54,22; 29,35; 17,$68 ; 14,77 \mathrm{~cm}$, respectivamente, para o comprimento externo de carcaça, o perímetro torácico, a largura do tórax e a largura de garupa, além da espessura da gordura, que apresentou média de $0,28 \mathrm{~mm}$.

A cada unidade percentual de concentrado houve acréscimo de aproximadamente $0,000263 \mathrm{~kg}$ no valor da compacidade da carcaça. Isto ocorre porque, com o aumento de seu peso (Tabela 5), a carcaça se torna relativamente curta, larga e compacta, como observado por Oliveira et al. (1998), que relataram coeficiente de correlação de 0,98 entre a compacidade da carcaça e o peso da carcaça fria.

Observaram-se valores decrescentes para compacidade da carcaça, o que indica redução na deposição de tecido por unidade de comprimento, em torno de $0,003645 \mathrm{~kg} / \mathrm{cm}$ a cada unidade percentual de farelo de babaçu na dieta. 
Tabela 5 - Medidas lineares da carcaça e dos cortes de ovinos mantidos com dietas contendo farelo de babaçu

\begin{tabular}{|c|c|c|c|c|c|c|c|}
\hline \multirow[t]{2}{*}{ Variável } & \multicolumn{4}{|c|}{ Nível de farelo de babaçu (\%) } & \multirow[t]{2}{*}{$\mathrm{CV}(\%)$} & \multirow[t]{2}{*}{ Equação de regressão } & \multirow[t]{2}{*}{$\mathrm{r}^{2}$} \\
\hline & 0 & 10 & 20 & 30 & & & \\
\hline Comprimento interno da carcaça, $\mathrm{cm}$ & 50,66 & 49,16 & 47,16 & 44,60 & 6,44 & $\hat{\mathrm{Y}}=50,9198-0,200472 * \mathrm{FB}$ & 0,99 \\
\hline Comprimento externo da carcaça, $\mathrm{cm}$ & 56,16 & 55,83 & 53,50 & 51,40 & 6,46 & $\hat{\mathrm{Y}}=54,22$ & - \\
\hline Comprimento da perna, $\mathrm{cm}$ & 36,16 & 29,50 & 26,66 & 27,00 & 7,03 & $\hat{\mathrm{Y}}=30,2028-0,126258 * \mathrm{FB}$ & 0,82 \\
\hline Profundidade do tórax, $\mathrm{cm}$ & 32,16 & 29,66 & 28,16 & 27,40 & 14,50 & $\hat{Y}=29,35$ & - \\
\hline Largura do tórax, $\mathrm{cm}$ & 20,08 & 18,58 & 17,08 & 15,00 & 22,37 & $\hat{Y}=17,68$ & - \\
\hline Largura da garupa, $\mathrm{cm}$ & 15,66 & 15,91 & 14,00 & 13,50 & 14,80 & $\hat{\mathrm{Y}}=14,77$ & - \\
\hline Perímetro da garupa, $\mathrm{cm}$ & 19,66 & 19,33 & 18,00 & 15,90 & 12,19 & $\hat{\mathrm{Y}}=20,1038-0,123899 * \mathrm{FB}$ & 0,90 \\
\hline Área de olho-de-lombo, $\mathrm{cm}^{2}$ & 11,23 & 11,87 & 8,20 & 6,71 & 16,66 & $\hat{\mathrm{Y}}=12,0784-0,0170892 * \mathrm{FB}$ & 0,81 \\
\hline Espessura de gordura, $\mathrm{mm}$ & 0,32 & 0,30 & 0,31 & 0,22 & 55,62 & $\hat{\mathrm{Y}}=0,28$ & - \\
\hline Compacidade da carcaça, $\mathrm{kg} / \mathrm{cm}$ & 0,274 & 0,262 & 0,212 & 0,168 & 7,47 & $\hat{\mathrm{Y}}=0,284528-0,00364563 * \mathrm{FB}$ & 0,95 \\
\hline
\end{tabular}

FB = nível de farelo de babaçu.

* Significativo a $5 \%$ de probabilidade pelo teste $\mathrm{t}$.

ns Não-significativo.

Esse resultado é reflexo direto do menor peso de abate dos animais, em conseqüência da baixa ingestão de energia metabolizável quando o farelo de babaçu foi adicionado à dieta, bem como do baixo potencial genético para carne dos ovinos estudados, pois Sousa Jr. (2003) não observaram diferenças significativas da compacidade da carcaça, que variou de 0,27 a 0,29, em ovinos Santa Inês mantidos com dietas contendo farelo de babaçu em substituição parcial de até $30 \%$ do farelo de soja na terminação de ovinos.

Por outro lado, Mattos (2006) reporta que baixos valores de compacidade da carcaça não são desejáveis para obtenção de carcaças de qualidade. Daí a importância de se obter carcaças mais pesadas e de animais jovens. Russo et al. (2003), estudando os processos de obtenção de carcaça em ovinos na Europa, relataram que o aumento do peso da carcaça resultou em maiores comprimentos e compacidades e observaram também que as carcaças mais pesadas possuíam diferentes morfologias e melhores conformações.

\section{Conclusões}

O uso do farelo de babaçu em nível acima de $10 \%$ na dieta afeta negativamente os pesos e rendimentos, bem como os cortes comerciais e as medidas lineares, de carcaças de ovinos sem padrão racial definido.

\section{Literatura Citada}

ALVES, K.S.; CARVALHO, F.F.R.; FERREIRA, M.A. et al. Níveis de energia em dietas para ovinos Santa Inês: características de carcaça e constituintes corporais. Revista Brasileira de Zootecnia, v.32, n.6, p.1927-1936, 2003 (supl. 2).

COLOMER-ROCHER, F.C.; MORAND-FEHR, P.; KIRTON, A.H. et al. Métodos normalizados para el estudio de los caracteres cuantitativos y cualitativos de los canales caprinas y ovinas. Cuadernos INIA, v.17, p.11-18, 1987.

FIGUEIREDO, E.A.P.; SIMPLÍCIO, A.A.; RIERA, G.S. et al. Preliminary studies on the carcass characteristics. Pesquisa Agropecuária Brasileira, v.17, n.6, p.951-960, 1982.

FURUSHO-GARCIA, I.F.F.; PÉREZ, J.R.O.; BONAGURIO, S. et al. Estudo dos cortes da carcaça de cordeiros Santa Inês puros e cruzas Santa Inês com Texel, Ile de France e Bergamácia. Revista Brasileira de Zootecnia, v.33, n.2, p.453-462, 2004.

GONZAGA NETO, S.; SILVA SOBRINHO, A.G.; LOPES, N.M.B. et al. Características quantitativas da carcaça de cordeiros deslanados Morada Nova em função da relação volumoso:concentrado na dieta. Revista Brasileira de Zootecnia, v.35, n.4, p.14871495, 2006.

INSTITUTO BRASILEIRO DE GEOGRAFIA E ESTATÍSTICA IBGE. Pesquisa Pecuária Municipal. Disponível em: <www.ibge.gov.br> Acesso em: 5/8/2006.

KIRTON, A.H.; CARTER, A.H.; CLARKE, J.N. et al. Comparisons of $15 \mathrm{ram}$ breeds for export lamb production 2. Proportions of export cuts and carcass class. New Zealand Journal of Agricultural Research, v.39, p.333-340, 1996.

MATTOS, C.W.; CARVALHO, F.F.R.; DUTRA JR., W.M. et al. Características de carcaça e dos componentes não-carcaça de cabritos Moxotó e Canindé submetidos a dois níveis de alimentação. Revista Brasileira de Zootecnia, v.35, n.5, p.2125-2134, 2006.

NATIONAL RESEARCH COUNCIL - NRC. Nutrient requirements of sheep. 6.ed. Washington, D.C.: National Academy Press, 1985. 99p.

OLIVEIRA, N.M.; OSÓRIO, J.C.S.; SELAIVE-VILLARROEL, A. et al. Produção de carne em ovinos de cinco genótipos. 5. Estimativas de qualidade e peso de carcaça através do peso vivo. Ciência Rural, v.28, n.4, p.665-669, 1998.

OSÓRIO, J.C.S.; OSÓRIO, M.T.M.; OLIVEIRA, N.M. et al. Qualidade, morfologia e avaliação de carcaças. Pelotas: Universidade Federal de Pelotas, 2002. 194p.

RUSSO, C.; PREZUISO, G.; VERITÁ, P. EU carcass classification system: carcass and meat quality in light lambs. Meat Science, v.64, p.411-416, 2003. 
SILVA SOBRINHO, A.G. Aspectos quantitativos e qualitativos da produção de carne ovina. In: REUNIÃO ANUAL DA SOCIEDADE BRASILEIRA DE ZOOTECNIA, 41., 2001, Piracicaba. Anais... Piracicaba: Fundação de Estudos Agrários Luiz de Queiroz, 2001. p.425-446.

SIQUEIRA, E.R. Efeito do sexo e do peso ao abate sobre a produção de carne de cordeiro. Morfometria da carcaça, pesos dos cortes, composição teciduais e componentes não constituintes de carcaça. Revista Brasileira de Zootecnia, v.30, n.4, p.1299-1307, 2001.

SOUSA JR., A. Substuição parcial do farelo de soja e milho por farelo de babaçu na terminação de ovinos. 2003. 58f. Dissertação (Mestrado em Ciência Animal) - Universidade Federal do Piauí, Teresina, 2003.

UNIVERSIDADE FEDERAL DE VIÇOSA - UFV. SAEG Sistema de análise estatística e genética. Viscosa, MG: 2001. $301 \mathrm{p}$.

VALADARES FILHO, S.C.; ROCHA JR.; CAPELE, E.R. Tabelas brasileiras de composição de alimentos para bovinos. Viçosa, MG: UFV; DZO; DPI, 2002. 297p.

WEISS, W.P. Energy prediction equations for ruminant feeds. In: CORNELL NUTRITION CONFERENCE FEED MANUFACTURES, 61., 1999, Ithaca. Proceedings... Ithaca: Cornell University, 1999. p.176-185. 